\title{
Agentes de Limpeza Pública: um Estudo Sobre a Relação Prazer/ Sofrimento no Ambiente Laboral
}

Public Cleaning Agents: A Study On The Relatinship Pleasure / Pain In The Workplace

Agentes De Limpieza Pública: Un Estudio Sobre La Relación Placer/Sufrimiento En El Ambiente Laboral

Claudia da Cruz Gomes \& Rafael Santos de Oliveira

Faculdade

Santíssimo

Sacramento
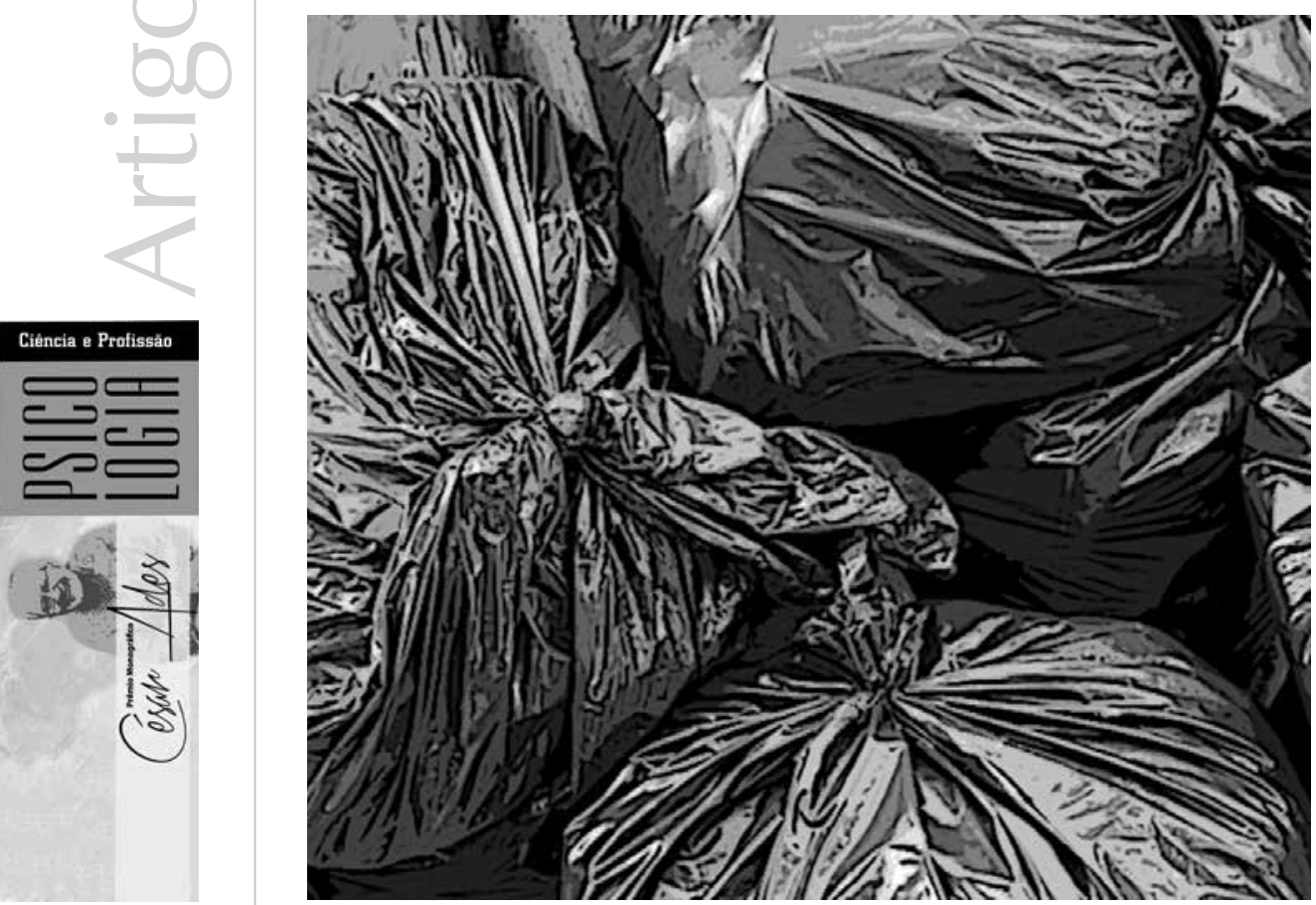
Resumo Este artigo relata uma pesquisa quantitativa realizada com uma amostra de 40 participantes de um total de 241 funcionários lotados no serviço de limpeza pública, pertencentes a uma empresa terceirizada prestadora de serviços de limpeza e manutenção junto à Prefeitura do Município de Alagoinhas-BA. A pesquisa teve como finalidade investigar as vivências de prazer/sofrimento no ambiente de trabalho, a partir das dimensões organização de trabalho e relações socioprofissionais. Como instrumento de coleta de dados, foi utilizada a Escala de Avaliação do Contexto de Trabalho (EACT) e a Escala de Indicadores de Prazer e Sofrimento no Trabalho (EIPST), cuja análise fora feita através da técnica da estatística descritiva, com o propósito de mensurar as percepções compartilhadas dos agentes de limpeza pública sobre o contexto de trabalho em que estão inseridos e as suas vivências de prazer e sofrimento no trabalho. Para o processamento dos resultados, foi aplicado o pacote estatístico SPSS (Statistical Package for Social Science), em que os dados obtidos foram sistematizados através de tabelas e de gráficos. Os resultados indicam que os agentes de limpeza pública estão sujeitos às contradições do contexto de trabalho, que geram prazer e sofrimento ao mesmo tempo, e que favorecem o uso eficaz de estratégias de defesa, evitando, assim, o adoecimento, embora a saúde possa estar sujeita a riscos em caso de falha dessas defesas.

Palavras-chave: Qualidade de vida no trabalho. Satisfação no trabalho. Stress ocupacional. Psicodinâmica do trabalho. Garis.

Abstract: This paper reports a quantitative study done with a sample of 40 participants from a total of 241 employees who work in the public cleaning service, belonging to a cleaning and maintenance service in the municipality of Alagoinhas-BA. The paper had as purpose to investigate the experiences of pleasure / pain in the workplace, from the dimensions organization of work and socio-professional relationships. The Evaluation of Work Context Scale (EACT) and the Indicators of Pleasure and Pain at Work Scale (EIPST) were used to collect data, whose analysis was done by the technique of descriptive statistics, with the purpose of measuring the shared perceptions of the public cleaning agents about the work context in which they live, and their experiences of pleasure and pain at work. For the processing of the results, we applied the statistical package SPSS (Statistical Package for Social Science), in which the data were systematized in tables and graphs. The results indicate that the cleaning agents are subject to public contradictions in the work context, which generates pleasure and pain while promotes the efficient use of defense strategies, thus preventing illness, although they may be subject to health risks in case of failure of these defenses.

Keywords: Quality of work life. Job satisfaction. Ocuppational stress. Labour psychodynamics. Street cleaners.

Resumen: Este artículo relata una investigación cuantitativa realizada con una muestra de 40 participantes de un total de 241 empleados que actúan en el servicio de limpieza pública, pertenecientes a una empresa tercerizada prestadora de servicios de limpieza y mantenimiento en el Ayuntamiento del Municipio de Alagoinhas-BA. La investigación tuvo como finalidad investigar las vivencias de placer/sufrimiento en el ambiente de trabajo, desde las dimensiones organización de trabajo y relaciones socio profesionales. Como instrumento de recolección de datos, fue utilizada la Escala de Evaluación del Contexto de Trabajo (EACT) y la Escala de Índices de Placer y Sufrimiento en el Trabajo (EIPST), cuyo análisis fue realizado a través de la técnica de la estadística descriptiva, con el propósito de medir las percepciones compartidas de los agentes de limpieza pública sobre el contexto de trabajo en el que están insertos y sus vivencias de placer y sufrimiento en el trabajo. Para el procesamiento de los resultados, fue aplicado el paquete estadístico SPSS (Statistical Package for Social Science), en que los datos obtenidos fueron sistematizados a través de tablas y de gráficos. Los resultados indican que los agentes de limpieza pública están sujetos a las contradicciones del contexto de trabajo, que generan placer y sufrimiento al mismo tiempo, y que favorecen el uso eficaz de estrategias de defensa, evitando, así, la enfermedad, aunque la salud pueda estar sujeta a riesgos en caso de fallo de esas defensas.

Palabras clave: Calidad de vida en el trabajo. Satisfacción en el trabajo. Estrés ocupacional. Psicodinámica del trabajo. Barrendero.

O lixo representa tudo aquilo que não tem valor e/ou utilidade para um determinado grupo social, trazendo a concepção de que deve ser colocado para fora das residências, fábricas e estabelecimentos comerciais para alguém levar. Nessa perspectiva, os indivíduos que trabalham com o lixo passaram, sob a lógica das sociedades modernas, a ser desprezados, 
desvalorizados, não reconhecidos pelo trabalho que desempenham, tornando-se seres invisíveis e sendo tratados também como lixo.

Em trabalho realizado com agentes de limpeza pública, Costa (2002) afirma que, em um grande aglomerado de pessoas, todo rosto tende a tornar-se insignificante, principalmente quando a pessoa está de uniforme. Nesse caso, a pessoa é vista como máquina que cumpre uma função, e não como ser humano, como se as pessoas enxergassem apenas a função social do outro. Nesse sentido, fica clara a existência de uma invisibilidade pública, uma percepção humana totalmente prejudicada e condicionada à divisão social do trabalho, em que se enxerga apenas a função, e não a pessoa.

Entende-se que lidar com o lixo representa todo um conjunto de problemas para a saúde dos indivíduos e para as condições ambientais (contaminação de solos, recursos hídricos, proliferação de vetores de doença). Nesse sentido, quando se considera esse contexto, percebe-se que o trabalho realizado por agentes de limpeza pública assume importância para a sociedade, pois esse tipo de atividade contribui para a prevenção de vários problemas de saúde pública e ambientais provenientes da disposição inadequada do lixo no âmbito das cidades.

No estudo realizado por Madruga e Loreiro (2002) sobre as cargas de trabalho dos coletores de lixo, constatou-se que esses trabalhadores estão expostos a uma carga psíquica constante, relacionada a uma atenção permanente exigida nas tarefas executadas, à insegurança, à falta de perspectiva, de reconhecimento e de valorização, a um ritmo diário de trabalho que se torna desgastante, à irritação em relação ao ruído constante, assim como aos desgastes físicos e emocionais devido à exposição ao perigo e à exigência da responsabilidade na tarefa.

Os conflitos e as contradições vivenciadas pelo sujeito no contexto de trabalho geram sofrimento psíquico que podem ser decorrentes da incompatibilidade entre a história individual do sujeito, perpassando por sonhos, desejos, necessidades, projetos, esperanças e uma organização de trabalho que não considera o indivíduo em sua totalidade. Segundo Dejours (1993/2010), o sofrimento é desencadeado quando o rearranjo da organização de trabalho não é mais possível, e a relação do trabalhador com essa organização é bloqueada e o indivíduo percebe-se impossibilitado de empreender modificações no ambiente de trabalho ou na atividade que realiza. Para lidar com esse sofrimento, os trabalhadores utilizam estratégias de defesa que têm como objetivo transformar o trabalho em fonte de prazer.

As pesquisas de Dejours consolidaram-se como a teoria da psicodinâmica do trabalho, que compreende o ser humano no trabalho, na sua relação com os outros indivíduos e com a coletividade. Essa teoria parte do pressuposto que o trabalho é um lugar privilegiado para o exercício da palavra e da enunciação, e que, portanto, se situa como um operador fundamental de construção do próprio sujeito, fazendo a mediação entre inconsciente e campo social.

O prazer/sofrimento é conceituado como vivências de medo, angústia, liberdade de expressão, reconhecimento e insegurança, enquanto as estratégias de defesa tendem a responder às contradições vivenciadas na organização de trabalho, evitando-as ou transformando-as. Nesse sentido, sua utilização passa a ser uma questão de sobrevivência para os trabalhadores. 
Segundo Dejours,

para que os

trabalhadores

pudessem dar

conta do trabalho

prescrito e

correspondessem

às expectativas

da organização e

não adoecessem,

eles se utilizavam

de estratégias

defensivas, tais

como negação, individualismo,

cinismo viril, bancar

o avestruz 1 e

conformismo, entre

outras formas de

proteção contra

o sofrimento e de

manutenção do

equilíbrio psíquico

por possibilitar

uma forma de

mediação do

sofrimento.

1 Bancar o avestruz constitui uma estratégia de defesa em que o indivíduo nega a realidade, sendo esta dissimulada através da máscara da ignorância.
Para Mendes e Cruz (2004), o sofrimento é o resultado do confronto dos trabalhadores com as adversidades e as contradições encontradas no contexto de trabalho, quando estas não podem ser negociadas e efetivamente alteradas e superadas. $\mathrm{O}$ adoecimento é consequência e manifestação da intensidade do sofrimento vivenciado ou surge quando as estratégias de defesa contra ele fracassam.

Vários autores, como Dejours (1992), Dejours, Abdoucheli e Jayet (2010), Madruga e Loreiro (2002), Mendes e Cruz (2004) e Mendes e Ferreira (2001), entre outros, desenvolveram pesquisas sobre as vivências de prazer/sofrimento no contexto de trabalho e as estratégias defensivas para superar as contradições vividas no ambiente laboral.

Segundo Dejours, para que os trabalhadores pudessem dar conta do trabalho prescrito e correspondessem às expectativas da organização e não adoecessem, eles se utilizavam de estratégias defensivas, tais como negação, individualismo, cinismo viril, bancar $o$ avestruz ${ }^{1}$ e conformismo, entre outras formas de proteção contra o sofrimento e de manutenção do equilíbrio psíquico por possibilitar uma forma de mediação do sofrimento.

Dejours, Abdoucheli e Jayet definem estratégias de defesa como mecanismos que os trabalhadores utilizam para modificar, transformar e minimizar a percepção da realidade que os faz sofrer. Eles salientam ainda que a diferença entre a estratégia defensiva individual e as coletivas é que a primeira permanece sem a presença física do objeto, que se encontra interiorizado, enquanto a segunda depende da presença de condições externas que se sustentam no consenso de um grupo específico de trabalhadores.
O trabalho é caracterizado como fonte de prazer e de sofrimento, de acordo com Mendes (2007), pois há que se considerar a existência de forças contraditórias e conflitantes no ambiente de trabalho. Nessa perspectiva, qual é a relação que se estabelece entre a dinâmica prazer-sofrimento e a percepção que esses trabalhadores têm do seu contexto de trabalho?

Este estudo tem como finalidade investigar as vivências de prazer/sofrimento no trabalho de agentes de limpeza pública, a partir das dimensões organização de trabalho e relações socioprofissionais, buscando analisar a relação homem-trabalho e propor um aprofundamento e estabelecimento entre a variável organização de trabalho e saúde mental.

A importância dessa temática, portanto, incide sobre a dimensão social, na medida em que contribui para uma reflexão acerca da importância do labor dos agentes de limpeza pública, fundamental para a salubridade da população, e para o rompimento de estigmas em relação a essa atividade. Nesse sentido, essa reflexão pode despertar uma ampliação do exercício de cidadania para com esses trabalhadores, proporcionando maior inclusão social.

\section{Método}

\section{Participantes}

A pesquisa foi realizada com uma amostra de 40 participantes de um total de 241 funcionários lotados no serviço de limpeza pública, pertencentes a uma empresa terceirizada prestadora de serviços de limpeza e de manutenção junto à Prefeitura do Município de Alagoinhas-BA. A amostra caracterizou-se, predominantemente, por agentes de limpeza pública que exercem a 
tarefa de varrição das ruas, sendo $67,5 \%$ do sexo masculino e $32,5 \%$ do sexo feminino, em que $45 \%$ possui idade entre 23 a 30 anos, 35\%, entre 31 a 40 anos, e 20\% entre 41 a 48 anos; desses funcionários, 50\% possuem o ensino fundamental e $50 \%$ o ensino médio, com tempo de serviço que perfaz 71,7\% para os funcionários compreendidos entre 1 a 3 anos, 23,1\% para 4 a 7 anos e 5,2\% para 8 a 14 anos de serviços prestados junto à empresa, conforme a Tabela 1.

Tabela 1. Perfil demográfico dos participantes

\begin{tabular}{|c|c|c|c|}
\hline Características & & № & \%Válido \\
\hline \multirow{3}{*}{ Gênero } & Masculino & 27 & $67,5 \%$ \\
\hline & Feminino & 13 & $32,5 \%$ \\
\hline & Total & 40 & $100 \%$ \\
\hline \multirow{3}{*}{ Escolaridade } & Ensino Fundamental & 20 & $50 \%$ \\
\hline & Ensino Médio & 20 & $50 \%$ \\
\hline & Total & 40 & $100 \%$ \\
\hline \multirow{4}{*}{ Estado Civil } & Solteiro & 18 & $45 \%$ \\
\hline & Casado & 21 & $52,5 \%$ \\
\hline & Outros & 1 & $2,5 \%$ \\
\hline & Total & 40 & $100 \%$ \\
\hline \multirow{4}{*}{ Idade } & 23 a 30 anos & 18 & $45 \%$ \\
\hline & 31 a 40 anos & 14 & $35 \%$ \\
\hline & 41 a 48 anos & 8 & $20 \%$ \\
\hline & Total & 40 & $100 \%$ \\
\hline \multirow{4}{*}{ Tempo de Serviço } & 1 a 3 anos & 28 & $71,7 \%$ \\
\hline & 4 a 7 anos & 9 & $23,1 \%$ \\
\hline & 8 a 14 anos & 2 & $5,2 \%$ \\
\hline & Total & 39 & $100 \%$ \\
\hline
\end{tabular}

Fonte: Dados da pesquisa

\section{Instrumentos}

Como instrumentos de coleta de dados, foram utilizadas a Escala de Avaliação do Contexto de Trabalho - EACT e Escala de Indicadores de Prazer/Sofrimento no Trabalho - EIPST, ambas validadas por Mendes e Ferreira (2007), as quais fazem parte do Inventário sobre Trabalho e Riscos de Adoecimento - ITRA, que é um instrumento auxiliar de diagnóstico de indicadores críticos no trabalho, e que é composto por quatro escalas interdependentes. A finalidade desse inventário, de acordo com Mendes e Ferreira, é a mensuração de distintas e interdependentes modalidades de representações dos respondentes, relativas ao mundo do trabalho, sendo estas estruturadas em quatro categorias, a saber: a) descrição do contexto do trabalho - são as representações relativas à organização, às relações socioprofissionais e às condições de trabalho, que são avaliadas pela Escala de Avaliação do Contexto de Trabalho, b) descrição das exigências - são representações relacionadas ao custo físico, cognitivo e afetivo do 
trabalho, que são avaliadas pela Escala de Custo Humano no Trabalho, c) descrição do sentido do trabalho - são os aspectos pautados nas vivências de prazer e de sofrimento no trabalho, tendo como escala avaliativa a Escala de Indicadores de Prazer e Sofrimento no Trabalho, d) descrição dos efeitos do trabalho para a saúde, que são os perfis relativos às consequências, em termos de danos físicos e psicossociais, em que a Escala de Avaliação dos Danos Relacionados ao Trabalho é utilizada para mensurar tal perfil. A EACT e a EIPST fizeram parte de um instrumento que totalizou 55 itens, assim distribuídos: do 1 ao 23, refere-se à Escala de Avaliação do Contexto de Trabalho; do 24 ao 55, à Escala de Indicadores de Prazer/Sofrimento no Trabalho.

A EACT é uma escala do tipo likert, cujas opções de resposta são: 1 nunca, 2 - raramente, 3 - às vezes, 4 frequentemente, 5 - sempre, e teve como objetivo analisar as representações que os agentes de limpeza pública têm de seu contexto de trabalho com base em duas dimensões: organização do trabalho e relações socioprofissionais de trabalho. Essa escala foi validada por Mendes e Ferreira, e é composta por três fatores: organização do trabalho (OT), condições de trabalho (CT) e relações socioprofissionais (RS), e a EIPST, que é uma escala de frequência do tipo likert de 7 pontos, com variação de 0 a 6, validada em estudos de Mendes e Ferreira e que tem por finalidade avaliar a ocorrência das vivências de prazer e de sofrimento no trabalho nos últimos seis (06) meses, em que 0 equivale a nenhuma vez e 6 equivale a seis ou mais vezes. A escala possui 32 itens, que se dividem em quatro fatores, sendo dois para avaliar o prazer - realização profissional e liberdade de expressão -, e dois para avaliar o sofrimento - esgotamento emocional e falta de reconhecimento -, e é utilizada com o propósito de traçar um quadro epidemiológico da situação atual desses funcionários no que diz respeito ao seu bem-estar psíquico.

\section{Procedimentos de coleta de dados}

O instrumento de pesquisa foi aplicado individualmente na amostragem de 40 funcionários de limpeza pública do Município de Alagoinhas-BA, com o devido consentimento formal da empresa e dos participantes. A aplicação do referido instrumento teve duração média de 20 a 30min. Esses funcionários foram selecionados pelo livre e espontâneo interesse de participar da pesquisa.

\section{Procedimentos de análise de dados}

A análise dos instrumentos utilizados EACT e EIPST foi feita através da técnica da estatística descritiva, que teve o propósito de mensurar as percepções compartilhadas dos agentes de limpeza pública sobre o contexto de trabalho em que estão inseridos e as vivências de prazer e de sofrimento no trabalho. Para o processamento dos resultados, foi aplicado o pacote estatístico SPSS (Statistical Package for Social Science), em que os dados obtidos foram sistematizados através de tabelas e gráficos. Os resultados dos instrumentos estão integrados na discussão do trabalho, compondo um conjunto de dados que fornecem subsídios para o estabelecimento de relações, tanto do ponto de vista empírico quanto teórico, com o propósito de atender aos objetivos do estudo. 


\section{Resultados e Discussão}

A análise do trabalho real dos agentes de limpeza pública do Município de Alagoinhas-BA, em especial das equipes que exercem a função de varrição das ruas, possibilitou a construção de um panorama explicativo da interrelação homem - trabalho que proporcionou a identificação e a avaliação dos fatores realização profissional, liberdade de expressão, esgotamento profissional e falta de reconhecimento como critérios para a compreensão dos resultados obtidos nas vivências de prazer/sofrimento, assim como os fatores organização de trabalho e relações socioprofissionais para os resultados da avaliação do contexto de trabalho dessa categoria profissional.

\section{Avaliação das vivências de prazer/sofrimento no trabalho de agente de limpeza pública}

Partindo da análise da variável organização de trabalho, saúde mental e custo psíquico dessa atividade para os agentes de limpeza pública, através dos indicadores das vivências de prazer/sofrimento, obtém-se como resultados, por meio da Escala de Indicadores de Prazer e Sofrimento no Trabalho (EIPST), conforme as Tabelas 2, 3, 4 e 5, a média de cada fator da variável dependente prazer-sofrimento no trabalho. Levando-se em consideração que a EIPST é uma escala de seis pontos, em que o ponto 3 se apresenta como ponto médio, os resultados mostram-se de forma diferenciada para os fatores de prazer, ambos acima da média, com 4,22 para valorização, 3,83 para reconhecimento e 5,10 para orgulho pelo que faço, 4,80 realização profissional, e, para os fatores de sofrimento, têm-se 4,43 para falta de reconhecimento do meu esforço, 4,20 para insegurança e 4,36 para falta de reconhecimento do meu desempenho, todos acima da média.

A Tabela 2 apresenta os resultados descritivos do fator realização profissional e de seus itens, bem como da variável dependente prazer-sofrimento no trabalho.

Tabela 2. Realização profissional

\begin{tabular}{clc}
\hline Item & \multicolumn{1}{c}{ Descrição } & Média \\
\hline 55 & Orgulho pelo que faço & 5,10 \\
57 & Realização profissional & 4,80 \\
61 & Gratificação com as minhas atividades & 4,60 \\
60 & Identificação com as minhas tarefas & 4,68 \\
56 & Bem-estar & 4,90 \\
53 & Satisfação & 4,66 \\
58 & Valorização & 4,22 \\
54 & Motivação & 3,48 \\
59 & Reconhecimento & 3,83 \\
& & Escore médio \\
\hline
\end{tabular}

Fonte: Dados da pesquisa 
De acordo com essa tabela, observa-se que a média do fator realização profissional foi de 4,47, considerada uma avaliação mais positiva ou estado satisfatório, indicativo de alto grau de prazer no trabalho (Mendes \& Ferreira, 2007). Ao analisar os itens orgulho pelo que faço, realização profissional, gratificação com as minhas atividades, identificação com as minhas tarefas, bemestar e satisfação, nota-se que esses itens apresentaram as maiores médias, equivalendo a uma avaliação mais positiva ou estado satisfatório.

Na Tabela 3, encontram-se os resultados descritivos do fator liberdade de expressão e de seus itens, assim como o da variável dependente prazer-sofrimento no trabalho.

Tabela 3. Liberdade de expressão

\begin{tabular}{clc}
\hline Item & \multicolumn{1}{c}{ Descrição } & Média \\
\hline 52 & Cooperação entre os colegas & 4,77 \\
47 & Solidariedade entre os colegas & 4,49 \\
46 & Liberdade para falar sobre o meu trabalho com os colegas & 3,97 \\
48 & Confiança entre os colegas & 2,26 \\
50 & Liberdade para usar minha criatividade & 2,20 \\
49 & Liberdade para expressar minhas opiniões no local de trabalho & 2,42 \\
45 & Liberdade com a chefia para negociar minhas demandas & 2,65 \\
51 & Liberdade para falar sobre o meu trabalho com as chefias & $\mathbf{1 , 9 7}$ \\
& & $\mathbf{3 , 1 0}$ \\
\hline
\end{tabular}

Fonte: Dados da pesquisa

Em conformidade com a tabela acima, a média do fator liberdade de expressão foi de 3,10, o que nos leva a considerá-la uma avaliação moderada ou estado crítico, indicativos de situações-limite (Mendes \& Ferreira, 2007). Ao avaliamos os itens cooperação entre os colegas e solidariedade entre os colegas, percebe-se que eles mostram as maiores médias, o que corresponde a uma avaliação mais positiva ou estado satisfatório. Os itens liberdade para falar sobre o meu trabalho com as chefias, liberdade para usar a minha criatividade e confiança entre os colegas exibiram as menores médias, sendo consideradas avaliações moderadas.

A Tabela 4 demonstra os resultados descritivos do fator esgotamento profissional e de seus itens, assim como o da variável dependente prazer-sofrimento no trabalho.

Tabela 4. Esgotamento profissional

\begin{tabular}{|c|c|c|}
\hline Item & Descrição & Média \\
\hline 63 & Estresse & 3,77 \\
\hline 62 & Esgotamento emocional & 3,33 \\
\hline 66 & Frustração & 3,08 \\
\hline 64 & Insatisfação & 3,18 \\
\hline \multirow[t]{2}{*}{67} & Insegurança & 4,20 \\
\hline & Escore médio & 3,47 \\
\hline
\end{tabular}

Fonte: Dados da pesquisa 
Nessa tabela, observa-se que a média do fator esgotamento profissional foi de 3,47, o que corresponde a uma avaliação moderada ou estado crítico, indicativos de situações-limite, nas quais o custo negativo e o sofrimento no trabalho são potencializados (Mendes \& Ferreira, 2007). Analisando os itens estresse e esgotamento emocional, verifica-se que demonstram as maiores médias, sendo também por isso consideradas avaliações moderadas ou estados críticos. Ressalta-se que o item insegurança obteve média 4,20, o que indica uma avaliação mais negativa ou grave. A Tabela 5 mostra os resultados descritivos do fator falta de reconhecimento e de seus itens, bem como o da variável dependente prazer-sofrimento no trabalho.

Tabela 5. Falta de reconhecimento

\begin{tabular}{|c|c|c|}
\hline Item & Descrição & Média \\
\hline 71 & Desvalorização & 3,53 \\
\hline 69 & Falta de reconhecimento do meu esforço & 4,43 \\
\hline 72 & Indignação & 3,48 \\
\hline 70 & Falta de reconhecimento do meu desempenho & 4,36 \\
\hline 75 & Injustiça & 3,00 \\
\hline 73 & Inutilidade & 2,58 \\
\hline 74 & Desqualificação & 2,38 \\
\hline \multirow[t]{2}{*}{76} & Discriminação & 3,23 \\
\hline & Escore médio & 3,36 \\
\hline
\end{tabular}

Fonte: Dados da pesquisa

Segundo essa tabela, percebe-se que a média do fator falta de reconhecimento foi de 3,36, que é uma avaliação moderada ou estado crítico indicativo de situações-limite, nas quais o custo negativo e o sofrimento no trabalho são potencializados (Mendes \& Ferreira, 2007). A análise dos itens desvalorização, falta de reconhecimento do meu esforço, indignação e falta de reconhecimento do meu desempenho apresentaram as maiores médias, sendo que o item desvalorização é considerado uma avaliação moderada ou estado crítico, e os itens falta de reconhecimento do meu esforço $(4,43)$ e falta de reconhecimento do meu desempenho $(4,36)$ são considerados uma avaliação mais negativa ou grave.

Observa-se que os resultados obtidos (ver Gráfico 1), através das análises descritivas dos fatores da variável dependente prazer-sofrimento no trabalho, mostram que, em média, há uma avaliação considerada mais positiva ou estado satisfatório do fator realização profissional, indicando uma frequência elevada de vivências geradoras de prazer no trabalho de agente de limpeza pública na empresa analisada. O sofrimento é vivenciado moderadamente pela proximidade do resultado dos fatores falta de reconhecimento do meu esforço, insegurança e falta de reconhecimento do meu desempenho com o ponto médio da escala. Esse fato leva-nos a concluir que ambas estão presentes no trabalho desses profissionais, porém em níveis diferentes, o que demonstra que as situações de prazer/sofrimento não são excludentes, ainda que, para essa categoria profissional, ocorra o predomínio do prazer. 


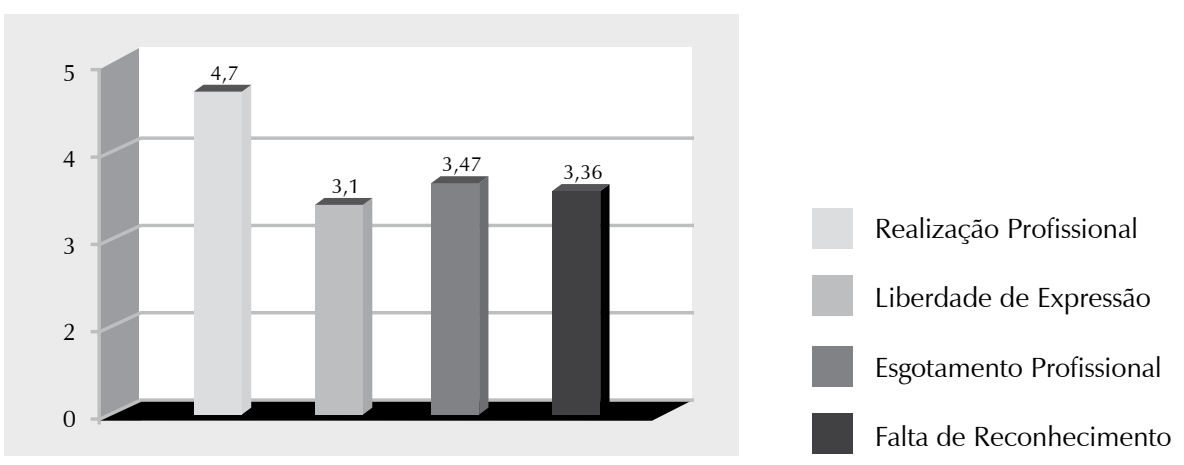

Gráfico1. Comparativo dos fatores da EIPST

A vivência orgulho pelo que faço, realização profissional, gratificação com as minhas atividades, identificação com as minhas tarefas, bem-estar e satisfação indicam que os funcionários estabelecem, de forma satisfatória, relações significativas com sua atividade laboral, com os colegas e com as chefias, demonstrando que o contexto oferecido apresenta condições necessárias para o trabalho ser fonte de prazer, e não de sofrimento. Sentir valorização no trabalho significa que o indivíduo o considera importante para si mesmo, para a empresa e para a sociedade, demonstrando, assim, um reforço positivo na autoimagem que está relacionada ao orgulho pela atividade desempenhada, à realização profissional, ao sentir-se útil e produtivo, tendo assim mais espaço para as vivências de prazer do que para as de sofrimento.

Em relação às vivências de sofrimento, os resultados mostram a presença de estresse no trabalho, uma vez que esses trabalhadores estão submetidos a atividades cansativas, desagradáveis, repetitivas, com sobrecarga, o que gera esgotamento emocional, frustrações, desânimo, desvalorização e insatisfação, o que significa também que estão submetidos a um sistema injusto de avaliação de desempenho bem como a injustiças ligadas ao exercício do poder.

No estudo realizado por Santos (1994) sobre condições de saúde e trabalho dos coletores de lixo, verificou-se que o sistema de coleta de lixo apresenta condições inadequadas e insalubres, exposição a acidentes de trabalho, tarefas repetitivas e esgotamento emocional.

Isso significa que, para essa categoria profissional que apresenta resultados acima da média para a vivência de prazer no ambiente laboral, o trabalho é lugar de realização, de identidade, de valorização e de reconhecimento, o que nos leva, a partir de um ponto de vista dinâmico, à hipótese de que o sofrimento vivenciado está sendo enfrentado com estratégias de defesa, que pressupõem a negação do sofrimento.

Essa hipótese sugere que esses profissionais estão submetidos a uma organização de trabalho que favorece mais o sofrimento do que o prazer, ou ainda, a modos que permitem a negociação entre o indivíduo e a realidade de trabalho, o que oferece espaço para o sofrimento, mesmo que este possa ser enfrentado, considerando-se o resultado da vivência de prazer acima da média, que pode estar indicando o uso de estratégias de defesa.

A relação entre prazer/sofrimento no trabalho constitui vivência concomitante e própria ao trabalho, podendo haver prevalência de uma sobre a outra a depender do ambiente de trabalho. 
O trabalhador estará sempre a buscar o prazer e a evitar e/ou amenizar o sofrimento com o intuito de manter o equilíbrio psíquico, para assim não ser vítima do adoecimento e de riscos à saúde. Segundo Dejours (1992), a saúde psíquica não depende apenas de recursos do sujeito, mas, sobretudo, das estratégias de defesa coletivas.

Dessa forma, entende-se que a construção de estratégias de defesa articula-se ao uso da criatividade como forma de enfrentamento do sofrimento, o que significa, assim, que, apesar da predominância do prazer na função de agente de limpeza pública, esses trabalhadores buscam a redução do custo psíquico no trabalho através da não convivência com o sofrimento e, possivelmente, buscando estratégias para desenvolver o prazer no ambiente de trabalho.

\section{Análise do contexto de trabalho}

Analisar o contexto de trabalho é compreender como o trabalhador percebe a sua organização de trabalho e as relações socioprofissionais existentes em seu ambiente laboral, possibilitando uma análise sistemática dos fatores que podem influenciar na satisfação no trabalho, em um baixo nível de estresse ou em um adequado desempenho individual, grupal e organizacional.

Fazendo referência à análise do contexto de trabalho dos agentes de limpeza pública do Município de Alagoinhas - BA, observa-se que, em relação ao fator organização de trabalho, os itens 26, 27 e 30 obtiveram maiores médias, conforme a Tabela 6 . Tal resultado significa que os agentes de limpeza pública acham que o seu trabalho apresenta frequentemente ou sempre tarefas repetitivas, número insuficiente de funcionários para realizar as tarefas e forte fiscalização do desempenho, bem como demonstram uma avaliação mais negativa ou grave dessa organização de trabalho, o que leva ao forte risco de adoecimento no trabalho e requer providências imediatas nas causas, com o fito de eliminá-las e/ou de atenuá-las (Mendes \& Ferreira, 2007).

Tabela 6. Organização de trabalho

\begin{tabular}{clc}
\hline Item & \multicolumn{1}{c}{ Descrição } & Média \\
\hline 22 & O ritmo de trabalho é acelerado. & 3,77 \\
23 & As tarefas são cumpridas com pressão temporal. & 3,29 \\
24 & Existem fortes cobranças de resultados. & 3,51 \\
25 & As normas para execução das tarefas são rígidas. & 3,26 \\
26 & Existe fiscalização do desempenho. & 4,54 \\
27 & O número de pessoas é insuficiente para se realizar as tarefas. & 4,03 \\
28 & Os resultados esperados estão fora da realidade. & 2,54 \\
30 & As tarefas são repetitivas. & 4,82 \\
31 & Falta tempo para realizar pausa de descanso no trabalho. & 3,23 \\
29 & Existe divisão entre quem planeja e quem executa. & 3,68 \\
32 & As tarefas executadas sofrem descontinuidade. & 2,50 \\
& & Escore médio \\
\hline
\end{tabular}

Fonte: Dados da pesquisa 
A Tabela 7 mostra os dados obtidos através da média dos itens analisados pelo fator relações socioprofissionais, em que os fatores com maiores médias são: o item 36 - os funcionários são excluídos das decisões, 37 - existem dificuldades na comunicação entre chefia e subordinados e 41 - falta de apoio das chefias para o meu desenvolvimento profissional demonstram uma percepção negativa desses fatores sociais no ambiente de trabalho, da seguinte forma: o item 36 indica uma avaliação mais negativa ou grave dessas relações, e os itens 37 e 41, respectivamente, mostram uma avaliação mais moderada ou estado crítico.

Tabela 7. Relações socioprofissionais

\begin{tabular}{llc}
\hline Item & \multicolumn{1}{c}{ Descrição } & Média \\
\hline 33 & As tarefas não estão claramente definidas. & 2,95 \\
34 & A autonomia é inexistente. & 3,25 \\
36 & Os funcionários são excluídos das decisões. & 4,10 \\
37 & Existem dificuldades na comunicação entre chefia e subordinados. & 3,15 \\
38 & Existem disputas profissionais nos locais de trabalho. & 2,95 \\
39 & Falta integração no ambiente de trabalho. & 2,80 \\
40 & A comunicação entre funcionários é insatisfatória. & 1,90 \\
41 & Falta apoio das chefias para o meu desenvolvimento profissional. & 3,33 \\
& & Escore médio
\end{tabular}

Fonte: Dados da pesquisa

Dessa forma, observa-se que, conforme o Gráfico 2, o fator organização de trabalho apresentase como um fator estressor que contribui para o adoecimento psíquico mais que as relações socioprofissionais. De acordo com Dejours (2005), a organização de trabalho compreende a divisão do trabalho e a divisão dos sujeitos, o que culmina em um distanciamento entre o trabalho real e o prescrito na realização das tarefas, e esse distanciamento associado à rigidez entre o trabalho prescrito e a organização real do trabalho exerce um papel primordial na determinação do sofrimento dos indivíduos.

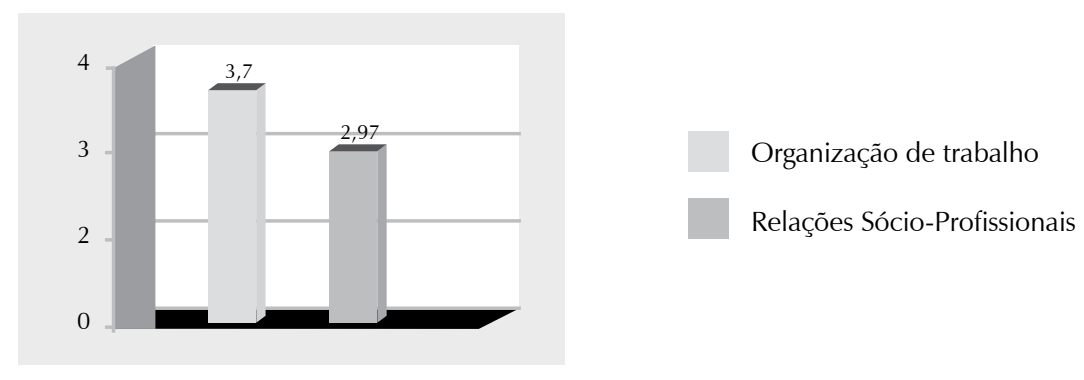

Gráfico 2. Comparativo dos fatores da EACT

\section{Considerações finais}

Esta pesquisa teve como finalidade investigar as vivências de prazer/sofrimento no ambiente de trabalho dos agentes de limpeza pública a partir das dimensões organização de trabalho e relações socioprofissionais, buscando investigar a relação homem-trabalho através da variável 
De acordo com

Dejours et al.

(2010), para

transformar um

trabalho fatigante em trabalho

equilibrante, é preciso flexibilizar a sua organização, de modo a dar maior liberdade

ao trabalhador para rearranjar seu modo operatório e para encontrar os gestos que são capazes

de the fornecer prazer, isto é, uma expansão ou uma diminuição de sua carga psíquica de trabalho. organização de trabalho e saúde mental. Pode-se considerar que a escolha do campo de pesquisa foi adequada, já que possibilitou o acesso ao fenômeno a que se propôs estudar (vivências de prazersofrimento), levando ao aprofundamento dos conceitos estudados na fundamentação teórica, ampliando o conhecimento a respeito desse assunto que é tão relevante para atualidade. Em consonância com os resultados encontrados, pode-se afirmar que os objetivos foram alcançados, sendo possível verificar a presença das vivências de prazer-sofrimento na amostragem analisada e a dinamicidade dessas vivências.

Com base na análise dos resultados, verificouse que as vivências de prazer e de sofrimento estão presentes no trabalho de agente de limpeza pública na empresa analisada, o que as torna coerentes com os estudos apresentados por Dejours (1992), Dejours et al. (2010), Madruga e Loreiro (2002), Mendes e Cruz (2004), Mendes e Ferreira (2001) e Vilela (2010), entre outros, que afirmaram que essas duas vivências coexistem nas experiências dos trabalhadores.

Percebe-se, na amostra analisada, a presença de indicadores que atendem aos interesses da organização, sendo um deles o medo do desemprego. Essa questão foi abordada por Dejours et al. (2010), ao enfatizar o quanto a condição de desempregado é eliciadora de sofrimento, ressaltando os autores que essa condição pode tornar-se uma forte arma ideológica para a organização, uma vez que os trabalhadores, por medo do desemprego, se habituam à organização, e quando não conseguem mais habituar-se, utilizam-se de estratégias de defesa contra o sofrimento ou o manifestam no corpo, por meio das doenças psicossomáticas.

As características da organização do trabalho e a divisão das pessoas encontradas na organização estudada, em alguns momentos, favorecem as vivências de prazer, mas, em outros, favorecem o desenvolvimento das vivências de sofrimento. Isso demonstra que as situações de prazer/sofrimento não são excludentes, ainda que, para essa categoria profissional, ocorra o predomínio do prazer.

De acordo com Dejours et al. (2010), para transformar um trabalho fatigante em trabalho equilibrante, é preciso flexibilizar a sua organização, de modo a dar maior liberdade ao trabalhador para rearranjar seu modo operatório e para encontrar os gestos que são capazes de lhe fornecer prazer, isto é, uma expansão ou uma diminuição de sua carga psíquica de trabalho. Assim, maior flexibilização das atividades, dos horários, dos relacionamentos e da abertura para o uso das habilidades e da liberdade, tanto de expressão quanto de ação dos trabalhadores, para que eles se identifiquem mais em seu trabalho, constitui uma possibilidade do aumento das vivências de prazer, conforme os estudos de Dejours $(1992,2010)$ e de Mendes (2007).

Pelas análises realizadas, observou-se que a empresa estudada tem condições de melhorar a organização do trabalho, que se caracteriza pela existência de tarefas repetitivas, número insuficiente de funcionários para realizar as tarefas e forte fiscalização do desempenho, estabelecidos muito mais pelas necessidades das demandas do que pelas características dos trabalhadores que realizam as atividades, pelo significado e sentido do trabalho, que são muito mais voltados para a provisão de necessidades materiais do que de realizações e aspirações pessoais.

Pretende-se buscar, no trabalho, o aumento cada vez maior das possibilidades de vivências de prazer e de redução do sofrimento, promovendo-se mais saúde e satisfação ao trabalhador, sendo desenvolvida, constantemente, uma organização do trabalho em que haja 
maior valorização dos fatores gratificação e liberdade no ambiente laboral.

Dessa forma, busca-se ampliar o campo de estudo em relação às organizações bem como no tocante ao desenvolvimento da psicodinâmica do trabalho, que tem sido uma teoria importante para a compreensão dos fenômenos psíquicos vivenciados nesse contexto. Ressalta-se que, historicamente, tais fenômenos eram desconsiderados nos estudos das organizações, mas têm se tornado fonte de ampliação científica e de melhoria dentro das próprias organizações. Assim, dentre as possibilidades de futuras pesquisas levantadas com base neste estudo, pode-se sugerir a investigação de quais estratégias coletivas de defesa são elaboradas pelos agentes de limpeza pública para superar, ressignificar ou minimizar as situações conflitivas no ambiente de trabalho.

Portanto, entende-se que esta pesquisa também contribuiu como fonte para novas perspectivas e visões sobre a relação saúde - trabalho, em especial dos agentes de limpeza pública, uma vez que, nessa área, se observam poucos artigos científicos voltados para a dinâmica prazer/ sofrimento dessa categoria profissional tão imprescindível para a questão da salubridade da nossa sociedade. 


\section{Claudia da Cruz Gomes}

Graduada em Psicologia pela Faculdade Santíssimo Sacramento, Alagoinhas - BA - Brasil.

E-mail: claugomes1977@hotmail.com

\section{Rafael Santos de Oliveira}

Mestre em Psicologia Social e do Trabalho pela Universidade Federal da Bahia e docente da Faculdade Santíssimo Sacramento, Alagoinhas - BA - Brasil.

E-mail: rafaaoff@hotmail.com

Endereço para envio de correspondência:

Estrada Rio Branco, 85, Alagoinhas - Velha. CEP 48.030-070. Alagoinhas, BA. 
Costa, F. B. (2002). Garis: um estudo de psicologia sobre a invisibilidade pública. (Dissertação de mestrado). Programa de Pós-graduação do Instituto de Psicologia da Universidade de São Paulo, SP.

Dejours, C. (1992). A loucura no trabalho: estudo de psicopatologia do trabalho (3a ed.). São Paulo: Cortez - Oboré.

Dejours, C. (2005). O fator humano. Rio de Janeiro: Editora FGV.

Dejours, C., Abouceheli, E., \& Jayet, C. (2010). Psicodinâmica do trabalho: contribuições da escola dejouriana à análise da relação prazer, sofrimento e trabalho (11a reimp.). São Paulo: Atlas. (Trabalho original publicado em 1993).

Madruga, R. B., \& Loreiro, M. B. (2002). Cargas de trabalho encontradas nos coletores de lixo domiciliar - um estudo de caso. (Dissertação de mestrado). Programa de PósGraduação em Engenharia de Produção, Universidade Federal de Santa Catarina. Florianopólis, SC.

Mendes, A. M. B., \& Cruz, R. M. (2004). Trabalho e saúde no contexto organizacional: vicissitudes teóricas. In A. Tamayo. (Org.), Cultura e saúde nas organizações (V. 1, pp. 59-76). São Paulo: Artmed.
Mendes, A. M., \& Ferreira, M. C. (2001). "Só de pensar em vir trabalhar, já fico de mau humor": atividade de atendimento ao público e prazer/sofrimento no trabalho. Estudos de Psicologia, 6(1), 97-108. doi: http://dx.doi.org/10.1590/ S1413-294X2001000100010

Mendes, M. A. (2007). Psicodinâmica do trabalho: teoria, método e pesquisas. São Paulo: Casa do Psicólogo.

Mendes, A. M., \& Ferreira, M. C. (2007). Inventário sobre trabalho e riscos de adoecimento - ITRA: instrumento auxiliar de diagnóstico de indicadores críticos no trabalho. In A. M. Mendes (Org), Psicodinâmica do trabalho: teoria, método e pesquisas. São Paulo: Casa do Psicólogo.

Santos, T.L.F. (1994), Relatório de pesquisa: estudo das condições de saúde e trabalho dos coletores de lixo da cidade de São Paulo. São Paulo: Fundacentro.

Vilela, E. F. (2010). Vivências de prazer-sofrimento no trabalho docente: um estudo em uma IES pública de Belo Horizonte. (Dissertação de mestrado). Faculdade Novos Horizontes, Belo Horizonte, MG. 